\title{
Atletismo e escola: interfaces com o conhecimento e desenvolvimento humano discente
}

Track and field and school: interfaces with student knowledge and human development

\author{
Rodolfo Silva da Rosa \\ Universidade do Estado de Santa Catarina, Brasil \\ rodolfodarosa@yahoo.com.br \\ Felipe Goedert Mendes \\ Universidade Federal de Santa Catarina, Brasil \\ felipe_goedert@hotmail.com \\ Ana Flávia Backes \\ Universidade Federal de Santa Catarina, Brasil \\ anafbackes@hotmail.com \\ Valmor Ramos \\ Universidade do Estado de Santa Catarina, Brasil \\ valmor.ramos@udesc.br \\ Edison Roberto de Souza \\ Universidade Federal de Santa Catarina, Brasil \\ Edsonrs@hotmail.com
}

\section{Resumo:}

Este estudo objetivou, a partir de uma intervenção pedagógica, com o conteúdo Atletismo enfatizando aspectos históricos e culturais, analisar suas interfaces com a formação, conhecimento e desenvolvimento humano dos alunos na Educação Física Escolar. Nesse processo de introduzir e contextualizar o tema experimentado optou-se pelo jogo como ferramenta de aprendizagem. As unidades foram determinadas pelas provas atléticas de correr, lançar e saltar. A experiência se desenvolveu numa turma de vinte e cinco alunos do $6^{\circ}$ ano do Ensino Fundamental de uma Escola Pública no município de São Jose (SC), Brasil. As aulas foram filmadas para posterior análise. Ainda, na avaliação, utilizou a entrevista semiestruturada empregando a técnica do grupo focal. Com a ida do Atletismo a escola, ao introduzir e resgatar elementos da história do homem, desenvolvendo conhecimento, as vivências lúdicas com o jogo, oportunizaram ao aluno, competências, saberes e valores, que contribuíram significativamente em seu desenvolvimento humano.

Palavras-Chave: Atletismo, Educação, Desenvolvimento Humano.

\section{Abstract:}

This study aimed at analyzing the interfaces of training, knowledge and human development of students in Physical School Education. It was based on a pedagogical intervention, with track and field content emphasizing historical and cultural aspects. In the process of introducing and contextualizing the tried theme, the game was chosen as a learning tool. The units were determined by the track and field tests of running, pitching and jumping. The experiment was carried out in a group of twenty-five students of the 6th grade of a Public School in the Municipality of São Jose (SC), Brazil. The classes were filmed for later analysis. For the evaluation, we used the semi-structured interview using the focal group technique. As a consequence of taking Track and field to school, we introduced and recovered elements of man's history, developed knowledge, playful experiences with the game and provided students with skills, knowledge and values that contributed significantly to their human development.

KEYWORDS: Track and field, Education, Human development. 


\section{INTRODUÇÃO}

O esporte, conteúdo tradicional do componente curricular da Educação Física é uma das manifestações culturais mais ensinadas para crianças e jovens no ambiente escolar. Devido ao fato desse estar presente hegemonicamente na escola, o professor deve adotar um trato pedagógico que abranja o esporte em sua complexa relação de conteúdo histórico e culturalmente produzido com o fazer prático (Carlan, Kunz, Fensterseifer, 2012).

Nessa perspectiva, os docentes devem oportunizar possibilidades pedagógicas que considerem os saberes dos alunos, os possibilitando ao desenvolvimento de valores e atitudes apropriadas a partir da aprendizagem de movimentos esportivos e de conceitos histórico e culturais (Machado, Galatti, Paes, 2014). A aprimorarão de gestos naturais e instintivos do homem são a base de movimentos técnicos do da modalidade do Atletismo, ao qual se compõe por corridas, saltos e lançamentos. Assim, atribuir sentidos e significados a um gesto perpassa pela mediação e reflexão do conteúdo, de sua evolução, associação e sua relação com a cultura e história da sociedade vigente (Daolio, 2002).

Nesse caminho, compreender que o ato de ensinar, deve ser direcionado como um saber, compreendendo o indivíduo de forma ampla e integral, considerando suas dimensões pessoais, sociais, morais e éticas (Morin, 2000). Dessa forma, na formação imbricada do ser, mundo e sujeito que se articulam de forma dialética, sustentando a premissa de que se aprende o mundo com o corpo em sua totalidade (Merleau-Ponty, 2011). E nessa perspectiva, em Delors (1998) o ensino deve priorizar uma educação da complexidade humana, oportunizando o desenvolvimento de quatro competências: cognitiva, produtiva, social e pessoal do aluno, permitindo a construção de saberes pertinentes a uma educação voltada para o indivíduo dentro de sua plenitude. A partir dessa visão, ao se pensar o esporte na escola devemos propor uma pedagogia de ensino centrado na compreensão e complexidade do fenômeno esportivo (Kunz, 2001).

No Ensino do Atletismo Escolar, em sua essência, deve-se propiciar ao discente um desenvolvimento amplo e um aprendizado significativo, sobretudo nos aspectos relacionados a compreensão do movimento dentro de um olhar cultural e plural (Rosa, Souza, Mendes, Wandscheer, Backes, 2017). Para Kunz (2001) a escola se configura como um espaço social cabível de fomentar práticas esportivas dentro de uma compreensão crítica, na qual possibilita estabelecer conexões com o contexto sociocultural. De fato, correr, saltar, arremessar e lançar são expressões corporais que representam destrezas humanas, favorecendo a relação do atletismo e com a cultura de homem e sociedade. Conquanto a opção pelo conteúdo Esporte como elemento para o ensino da História e possibilidades de formação humana deve ser oportunizado e sistematizado, cabe ressal tar que ainda assim este tem um principio de sistematização de uma matriz europeia que também devemos problematizar e refletir (Oliveira, 2008).

Assim, conhecer e relacionar a história do Atletismo com a do homem, em suas construções sociais e culturais, podem direcionar para um outro olhar acerca desse tema enquanto conteúdo curricular nas aulas de Educação Física Escolar. No âmbito da Escola o esporte enquanto um fenômeno sócio-cultural pode estimular diferentes aspectos formativos nos alunos. Nessa perspectiva ao adotarmos o jogo como um eixo norteador para se desenvolver o conteúdo atletismo, pode-se oportunizar e aguçar mais o interesse no envolvimento desses com o tema nesse ambiente.

Sob essa lógica, o objetivo deste estudo foi, a partir de uma intervenção pedagógica, com conteúdo histórico cultural do Atletismo, utilizando o jogo como ferramenta e estratégia didática, analisar suas interfaces com a formação, conhecimento e desenvolvimento humano dos alunos.

\section{Metodologia}

Pesquisa de cunho qualitativo e fenomenológico foi desenvolvida a partir de uma experiência pedagógica com o conteúdo histórico-cultural do Atletismo em uma escola pública do município de São 
José (SC). A partir de seu desenho metodológico, buscou-se estabelecer um olhar sobre o conhecimento de acordo com a Fenomenologia, compreendendo o mundo enquanto é vivido pelo sujeito (Gil, 2008). Assim, Para Merleau-Ponty (2011, p.1) “...a fenomenologia é também uma filosofia que repõe as essências na existência, e não pensa que se possa compreender o homem e o mundo de outra maneira senão a partir de sua "facticidade".

A pesquisa desenvolvida através de uma intervenção pedagógica com o Atletismo Escolar em 25 aulas de Educação Física, numa turma de $6^{\circ}$ ano do Ensino Fundamental, constituída por 20 alunos, sem conhecimento prévio ou vivência, com o a modalidade esportiva experimentada. Assim, a intervenção pedagógica, buscou compreender as interfaces desse conhecimento formativo com desenvolvimento humano, trilhado em consonância com a proposta curricular municipal e com o projeto político pedagógico da instituição de ensino.

Esta intervenção pedagógica, mediada e articulada na relação entre a teoria e a prática, problematizando a realidade e propondo alternativas de ação a partir dos conhecimentos apreendidos e das relações sociais estabelecidas, tendo o jogo como recurso peculiar e significativo da experiência com o atletismo, na aprendizagem, na identificação de sentimentos e de representações discentes.

$\mathrm{Na}$ direção de analisar os conteúdos dos jogos utilizados no desenvolvimento do conteúdo proposto, as 25 aulas ministradas foram filmadas, técnica que possibilitou na observação, a descrição e uma ampliação do olhar ao fenômeno pesquisado (Mauad, 2004), transcrição em Ficha de Análise de Conteúdo de Jogos, de Souza (2001) e, partir desses instrumentos, os mesmos foram categorizados e interpretados através da técnica de análise de conteúdo de Bardin (2011), na perspectiva de indicar suas possibilidades ao desenvolvimento humano dos alunos.

Utilizou-se também de uma entrevista semiestruturada com os alunos, através da técnica de grupo focal, para, de acordo com Morgan (1996), identificar aspectos relevantes ocorridos nas aulas experimentadas com o conteúdo proposto, o atletismo escolar. A entrevista ocorreu, sem interferências, no ambiente da intervenção pedagógica, com auxílio de um gravador e de uma filmadora, colocada em um ponto fixo de modo a captar a imagem e registrar a fala do grupo participante. Esta metodologia facilitou a interação e o interesse das crianças no diálogo com o pesquisador.

O estudo cumpriu os princípios éticos de acordo com a Resolução no 196 do Conselho Nacional de Saúde, sendo aprovado e registrado no Conselho de Ética em Pesquisa (CEP) da Universidade Federal de Santa Catarina (UFSC), sob o número 1.322.801.

\section{RESUltados E Discussão}

\section{Olhar discente sobre....}

A proposta de ensino, apresentada dialogicamente, com os alunos, pontou inicialmente, os elementos histórico-culturais constitutivos do Atletismo. Assim, abordou-se sua história imbricada com a da própria humanidade, sobretudo, na necessidade de sobrevivência e soberania do homem no planeta, o qual aprimorou destrezas e habilidade fundamentais, em seu ambiente hostil.

Nesse contexto histórico do atletismo, em Delors (1998) o ensino deve priorizar uma educação da complexidade humana, oportunizando o desenvolvimento de quatro competências: cognitiva, produtiva, social e pessoal. No cenário que se desenhou, a primeira competência provocada aos alunos, foi a cognitiva com a aquisição da linguagem, fatos e aspectos dos meios de comunicação sobre a modalidade do Atletismo. Neste momento, por meio de uma conversa acessível e de possível compreensão por todos, buscando o que os alunos sabiam sobre o Atletismo, seus fatos históricos e culturais, que na concepção de Delors (1998), a linguagem de fácil compreensão tem um papel fundamental na relação entre ensino e aprendizagem, entre professor e aluno. 
A intervenção pedagógica possibilitou aos alunos, também, no vivenciar e compartilhar os movimentos de correr, saltar e lançar, reflexões sobre suas próprias histórias. Dessa forma, o passado não deixa de existir, nem de mostrar cicatrizes que marcaram seus corpos e significados atribuídos durante as experiências e vivências em seus corpos (Merleau-Ponty, 2011).

Como primeira ação da intervenção pedagógica mostrou-se duas imagens, sendo a primeira o desenho de uma pista e, a segunda, fotos de atletas de destaque mundial no atletismo, tornando mais fácil a apreensão da linguagem da modalidade, despertando nos alunos o interesse em descobrir os significados das linhas no desenho da pista, além de, conhecer um pouco mais a respeito dos atletas apresentados, comportamentos confirmados nos trechos da observação realizada, ilustrada na figura 1 ,

Figura 1 - Apresentação de imagens e fotos referentes ao atletismo

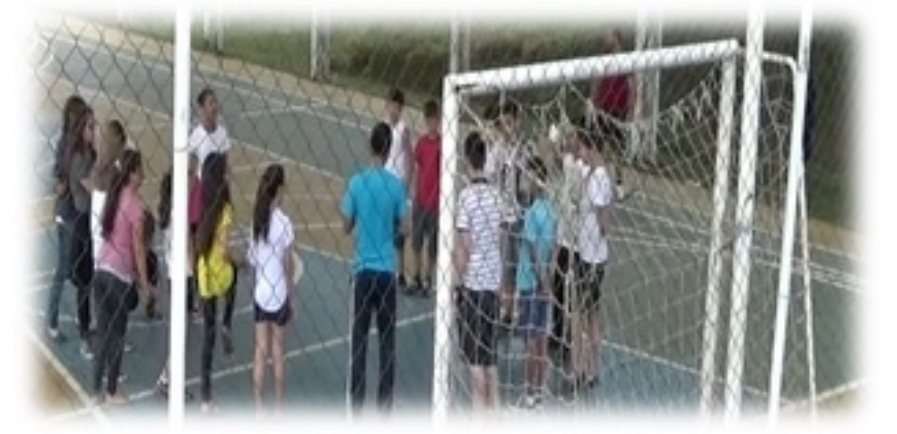

\begin{abstract}
A primeira resistência à proposta apresentada se deu em função da predominante cultura do futebol como conteúdo hegemônico. E a partir daí, o questionamento provável, surgiu! Um aluno interrogou quando teriam futebol, com apoio e cumplicidade de muitos. (O autor) Fonte: Arquivo do autor
\end{abstract}

A partir dessa resistência cultural e inicial acerca de novas possibilidades de se movimentar na escola, questionou-se sobre quais esportes e práticas corporais eram oferecidas na escola? De que maneira essas práticas se consolidavam? Com isso, percebeu-se a necessidade de ampliarmos os olhares para além da cultura dos jogos coletivos na escola, sobretudo, o futebol, discutindo novas possibilidades de movimento, caminhando de fato, na perspectiva, para uma ampliação do repertório motor cultural dos alunos.

Assim, no desenvolvimento de competência cognitiva, no saber conhecer sobre o atletismo, abordouse sua origem desde os primórdios com o homem pré-histórico até os dias atuais, ilustrando a temática com as fotos dos atletas de destaque. Ao retratar sobre a história das corridas, um fato foi marcante para promover um interesse inicial, comentou-se sobre o atleta norte-americano Jesse Owens e seu desempenho nas olimpíadas de Berlim, fato que gerou muita atenção da turma, pois, durante o período da intervenção, estarem pesquisando na disciplina de História, a segunda guerra mundial, em especial, temas sobre o nazismo e seu idealizador Adolf Hitler. Cabe ressaltar a possibilidade de se refletir sobre o processo de luta e das classes sociais nas diferentes modalidades esportivas, e, também, na sociedade de forma geral.

A inclusão de aspectos históricos e culturais do Atletismo, enquanto conteúdo da Educação Física ocorreu em sintonia e equilíbrio com a aprendizagem pedagógica de seus aspectos técnicos, táticos e socioeducativos, visando à formação integral pela reflexão dos sujeitos da intervenção, com a prática da modalidade (Machado, Galatti, Paes, 2014).

Dentro os diversos jogos experimentados na proposta pedagógica do ensino do atletismo, alguns, foram selecionados, intencionalmente, para análise de suas interfaces com o desenvolvimento humano dos alunos. Além da reflexão sobre a história e cultura do Atletismo, os mesmos foram elencados a partir dos movimentos essenciais, da modalidade, correr, saltar e lançar e suas relações com os cenários contextuais da sociedade. 


\section{o correr na escola...}

Ao se estabelecer relações com os motivos do correr na história, os alunos foram colocados como homens primitivos, na perspectiva de utilizar a ação de correr de maneira rápida, para sobrevivência e preservação da espécie. Ao adotar o jogo como uma ferramenta para se ensinar atletismo, podendo ressignificar o esporte nas aulas de Educação Física, ampliando além da dimensão do saber fazer, perspectivando uma ampliação para além do gesto técnico dentro de sentidos e significados mais críticos e amplos.

Ao utilizarmos jogos para se ensinar o atletismo, os tradicionais podem ser pensados como uma estratégia pedagógica de formação e desenvolvimento e, nessa direção, na perspectiva de oportunizar nos alunos o germinar de saberes, competências e valores cruciais para seu desenvolvimento humano (Souza, 2001).

$\mathrm{Na}$ percepção e interpretação do Jogo Pega-Pega Congela desenvolvido na experiência pedagógica, estabeleceu-se à analise dentro de dois cenários e ações distintas, pegar e fugir. No primeiro, os pegadores tinham que decidir qual ação estabelecer e com isso potencializavam sua tomada de decisão para alcançarem o objetivo na atividade. No segundo cenário, o dos fugitivos, autodeterminados, lutavam para se manterem protagonista da atividade, desenvolvendo e aprimorando valores sociais na comunicação e elaboração de estratégias com colegas capturados. Nas duas funções, a determinação e tomada de decisão são comportamentos que deveriam ser estimulados nas demais atividades pedagógicas escolares, contribuindo no desenvolvimento dos alunos como agentes sociais (Delors, 1998).

A motivação e participação foi muito boa, sobretudo, por ser um jogo conhecido dos alunos, e isso ocorre, conforme Leontiev (1978, p. 108) quando existe um motivo “...uma vez que a necessidade encontra sua determinação no objeto (se "objetiva" nele), o dito objeto torna-se motivo da atividade, aquilo que a estimula”.

Foi possível observar, no comportamento social do jogo de pega-pega, ressignificado, algumas indecisões na tentativa de salvar ou descongelar os demais participantes aprisionados. Primeira motivação na tomada de decisão estava vinculada diretamente com o aspecto afetivo. Qualquer tentativa de salvar estava imbricada aos seus amigos. Tal situação nos remeteu a refletir sobre as escolhas e a importância da postura ética e de bondade com todos, discutindo sobre a dubiedade do jogo e esporte.

Essa situação, vivenciada no jogo, encontra ressonância nos estudos de André e Mandigo (2013) que discutiram sobre o bem e o mau no meio esportivo, apontando como importante, o problematizar sobre os caminhos e a dubiedade do jogo e esporte nas aulas de Educação Física.

Dessa forma, com o intuito de desenvolver valores mais humanos e sociais, sugeriu-se no desenvolvimento do jogo Alerta, ações mais positivas entre os participantes ao estabelecer que o descongelamento do colega aprisionado só se efetivaria através de um abraço. Mesmo com receio inicial, os alunos aceitaram a proposta e partilharam abraços desajeitados, desconfiados, porém sinceros, estabelecendo novos laços, ampliando suas relações afetivas.

Assim, após a reflexão, quando verificamos o nível de dedicação de cada um, independente do objetivo do jogo (correr), os participantes se dedicaram ao máximo dentro das suas tarefas. E nesse contexto, cabe ressaltar um breve momento que ilustra, após a mediação, o aprender a conviver entre eles, conforme a observação e a figura 2: 
Figura 2 - Interação e mediação os alunos

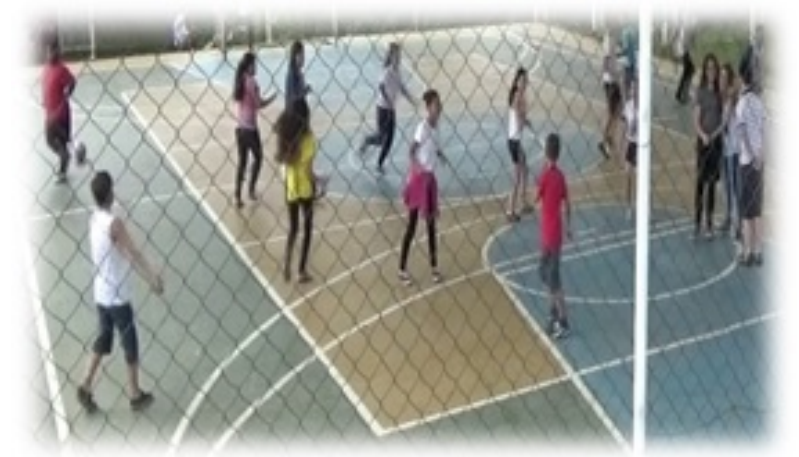

\begin{abstract}
Ao optarem em abraçar os colegas que tinham maior afinidade, discutiu-se sobre a possibilidade de deixarem um colega na selva para os animais selvagens devorarem, pois esse era o ambiente simbólico estabelecido. Assim, após a intervenção docente acabaram abraçando à todos, independentemente da relação que estabeleciam fora do momento da aula. Logo, houve participação de todos os alunos, tornando o ambiente do jogo, um espaço de alegria, prazer e descontração e convivência social. Fonte: arquivo do autor.
\end{abstract}

Assim, nesse ambiente social reconstruído, a relação se ampliou cultivando valores éticos e de bondade, compartilhando sensações e a consolidação de amizade e respeito entre todos.

Em relação à simbologia da tarefa estabelecida, a invariante imediatamente recrutada pela situação motora é transponível, não se constituindo apenas, numa experiência corporal, mas, uma experiência do corpo no mundo, dando sentido motor a determinada ordem verbal (Merleau-Ponty, 2011). Dessa forma, o poder incipiente do movimento em criar sentidos e significados, por ele e além dele pode fomentar outros aspectos simbólicos dentro de uma aproximação real, resgatando o representar, sentir, perceber e imaginar.

Outro jogo aplicado na experiência e contextualização da Corrida, o Jogo de Resistência de Entrega da Mensagem, explicou-se que em determinado período histórico as mensagens eram entregues de diferentes maneiras, e no caso referenciou-se sobre o surgimento da maratona. Assim, os alunos deveriam entregar uma mensagem distante e necessitavam correr por um longo período, consolidando o entendimento das provas de meio-fundo e fundo e os alunos conheceram sobre o meio-fundista Joaquim Cruz que fez história nos jogos de Los Angeles, em 1984, com o ouro emocionante nos $800 \mathrm{~m}$ rasos. Na perspectiva de desenvolvimento da competência cognitiva, o ensino do atletismo em ambiente escolar, pode contribuir para ampliar os saberes referentes à história do ser humano (Rosa, Souza, Mendes, Wandscheer, Backes, 2017).

As corridas de resistência são provas que exigem uma demanda fisiológica e psicológica muito elevada, devendo o atleta conhecer suas potencialidades. Dessa forma, a competência pessoal foi experimentada no exercício da autodeterminação e o autoconhecimento, permitindo aos alunos conhecerem seus limites, fragilidades e potencialidades. Reforçando essa concepção, Morin (2000) entende como importante que cada ser conheça a si mesmo, pois, quando o indivíduo não conhece a si próprio, ele não pode conhecer nada que está a sua volta.

Cabe neste momento, ressaltar uma situação ocorrida no jogo da resistência, quando após a segunda volta, uma aluna estava visivelmente cansada, manteve-se na corrida e, parou de executar a atividade quando observou a desistência de outras colegas. Ao, ser questionada, sobre não ter interrompido a corrida antes, declarou: "não queria ser a primeira".

As corridas de resistência, como as maratonas são marcadas por observadores nos arredores das provas, incentivando os competidores, renovando suas energias e os motivando para que continuem de tal maneira até o final. $\mathrm{Na}$ escola, não foi diferente, pois, os demais alunos, que já haviam realizado a corrida, ficavam motivando os demais a concluir o desafio do jogo, estendendo suas mãos para os que ainda estavam correndo baterem. 
Nessa situação, um aluno somente continuou até o final pelos incentivos e para surpresa de muitos, uma vez que o mesmo não costumava participar com frequência das atividades. Como descreve o relato e ilustra a figura 3:

Figura 3 - Foto da vibração e interação entre alunos

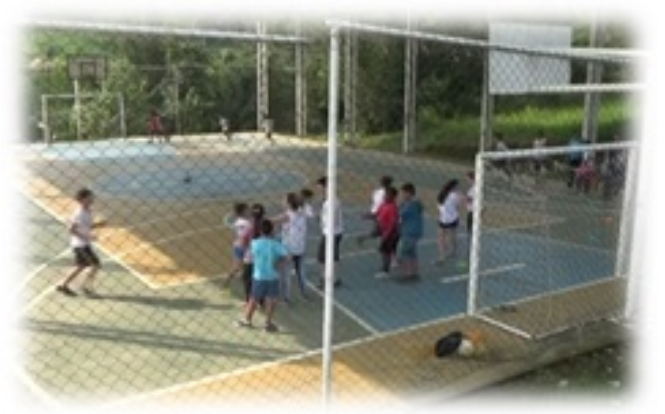

\footnotetext{
Um aluno demonstrando estar extremamente feliz comentou: "nem acredito que fiquei até o final, esperava participar apenas". Ele foi bastante resiliente em continuar o percurso, mesmo aparentando estar exausto. Para surpresa de muitos, pois, o mesmo não participava muito das atividades observadas anteriormente e assim não demonstrando interesse em atividades que exigiam esforço físico.

Fonte: arquivo do autor.
}

Desta forma, evidenciou-se que o jogo proposto provocou novas descobertas, além de promover o autoconhecimento e o fortalecimento da identidade de cada educando e o entendimento de que as provas de meio fundo e fundo requerem uma alta demanda fisiológica assim como uma preparação tática e psicológica adequada.

O elemento lúdico determinou situações que provocavam o divertimento nos alunos, pois quando corriam conversaram, desfrutando a companhia de um colega ao seu lado sem se preocuparem com o resultado final, como se faz em muitas corridas longas ao se correr ao lado de um companheiro ou mesmo um adversário. De fato, o jogo cativou muito os participantes e, neste sentido, é oportuno o pensamento de Huizinga (1980, p.13): “O jogo lança sobre nós um feitiço: é 'fascinante', 'cativante”".

A competência social do aluno, imbricada com a competência pessoal, valorizou o sentido de vida em comunidade, desenvolvendo autodeterminação, autoconfiança e resiliência no enfrentamento de desafios, superando limites pessoais e na percepção da importância do grupo na definição de metas e conquista de objetivos. Para Delors (1998), o desenvolvimento da competência pessoal é essencial ao autoconhecimento, sendo uma ferramenta importante para desencadear as demais dimensões do desenvolvimento humano.

\section{o lançar e arremessar na escola....}

$\mathrm{Na}$ dimensão das Provas Atléticas de Lançar e Arremessar, a experiência desenvolveu seus aspectos histórico-culturais, tendo como ferramenta, jogos que oportunizassem o experimentar do aluno com essas ações, estabelecendo nexos com a própria história do homem.

$\mathrm{Na}$ construção da identidade cultural e histórica com o atletismo, as ações do homem primitivo que utilizava o lançar para obter comida e também como forma de se proteger, foi uma discussão tecida, com os olhares dos alunos muito atentos.

Ao adentrar nos jogos de lançar, contextualizou-se sobre a idade da pedra, estimulando pelo jogo simbólico que os alunos deveriam caçar os animais. O elemento lúdico tornou-se um diferencial para que os alunos se direcionassem com maior entusiasmo para a atividade. Assim, no Jogo de Caça Primitiva, com discos coloridos, os alunos se motivaram a acertar o alvo, uma simples caixa de papelão com um desenho de um animal, no centro da quadra, interpretado como uma feroz besta selvagem do período pré-histórico. 
Percebeu-se nessa situação que a competência pessoal foi estimulada, pois quando entenderam que as demandas de espaço e material eram insuficientes, eles se auto organizaram, individualmente, para que todos pudessem participar e vivenciar o lançar o disco na caixa de papelão.

O sentido estético da brincadeira com os discos coloridos causou alvoroço e empolgação, no qual todos tentaram brincar com o objeto diferente. Tal situação pode ser ilustrada e corroborada com os achados de Freire e Goda (2008) aonde, crianças submetidas à construção de jogos, desenvolveram sintomas de enriquecimento dentro das atividades por intermédio do sentido estético dos objetos fabricados.

Os achados também apontam para a possibilidade de construção e utilização com materiais alternativos, Iora, Fiorenza, Rios, Rosa (2016) afirmam que para se desenvolver Atletismo na escola, não há necessidade de se ter materiais e espaços dentro de uma concepção de esporte institucionalizado. Nesse momento cabe levantar acerca das dificuldades que se apontam ao não se tratar do conteúdo atletismo no espaço escolar, como a falta de espaços, materiais e conhecimentos apropriados por parte do docente (Iora, Marques, 2013).

Ainda durante o experimentar do jogo simbólico, o foco no resultado ficou evidente quando se percebeu que o derrubar tornou-se mais prazeroso do que tentar acertar com lançamentos dos discos, conforme observado na Figura 4:

Figura 4 - Jogo de Caça Primitiva

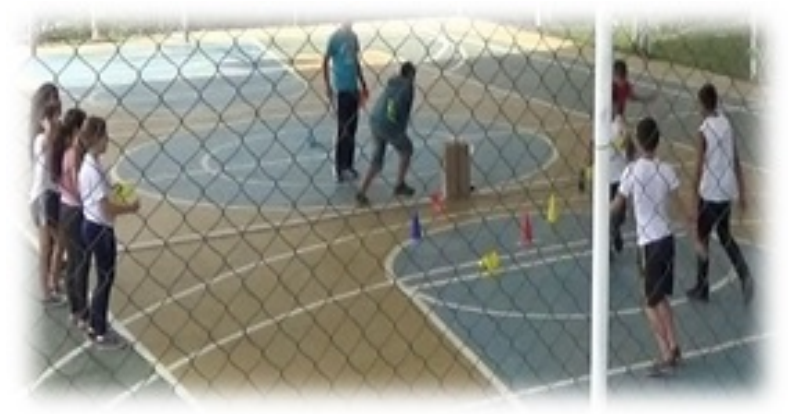

\footnotetext{
Um aluno estava com dificuldades em acertar o alvo (animal selvagem) e derrubou com a mão quase que de forma invisível e comemorou perpassando aos outros o seu êxito e a forma de conquista-lo, o que foi seguido pelos colegas ao se depararem com a mesma situação. Fonte: arquivo do autor.
}

A valorização dos resultados em detrimento do processo deve ser problematizada quando houver necessidade, conduzindo e oportunizando reflexões críticas aos alunos (Kunz, 2001, Iora, Marques, 2013). Assim, diante do exposto (figura 4) propôs-se uma reflexão coletiva, vislumbrando a organização na atividade e discutindo sobre princípios éticos e sobre as diferentes maneiras de lançar.

$\mathrm{Na}$ análise dos efeitos do jogo, o desenvolvimento da competência social e produtiva, ficou evidente na organização dos alunos para jogar de forma correta e coletiva, criando como estratégia uma espécie de onda para jogar. Assim, foram se ajustando às ações do anterior e do sucessor, para todos ficaram em sintonia enquanto grupo para tentarem abater os animais (cones e a caixa).

Num outro jogo, foi oportunizado aos alunos, lançar pedras que estavam nos arredores da escola, num terreno baldio e a partir do mesmo, discutiu-se sobre as provas atléticas, estabelecendo suas relações com a cultura ocidental. Nessa direção, discutiu-se que arremesso de peso, por exemplo, nasceu no Reino Unido, surgindo de manifestações folclóricas irlandesas e escocesas aonde os competidores arremessavam pedras de aproximadamente $25 \mathrm{~kg}$, também que havia provas de arremesso de pedras, precursoras do arremesso do peso, em festividades da civilização egípcia (Duarte, 2000). Nesse momento, problematizou-se sobre onde haviam no decorrer da historia manifestações da cultura de movimento similares aos movimentos do Arremesso de peso. Por final, nesta atividade os alunos tiveram a curiosidade de Abordamos as técnicas de execução, como o deslocamento linear ou técnica de O’Brian. inventado por Parry O’Brian e a execução rotacional que também é adotada no lançamento de disco. 
Dessa forma, ao ser utilizado o espaço rustico no entorno da escola e pedras que não serviam para algo útil, pode-se estabelecer relações expressivas para os alunos, podendo por meio da essência do movimento, compreender a construção histórica e cultural da prova de arremesso de peso, pois, para Merleau-Ponty (2011), o corpo, enquanto se move a si mesmo, inseparável de uma visão do mundo, adquiri e expressa o mundo cultural. No caso desse conteúdo nas aulas, os alunos puderam perpassando da experiência da rusticidade histórica até a complexidade do movimento técnico de O’brian, sentir e se marcarem corporalmente com a essência gestual impregnada de significados construídos histórica e culturalmente.

\section{saltar e as reflexões históricas e culturais}

No experimentar e perceber os saltos e suas diferentes possibilidades, seja nos planos vertical (altura), horizontal (distância) e sequencial (triplo), discutiu-se seus constructos histórico-culturais, introduzindo recortes de determinados momentos, além da evolução técnica dos mesmos. Sobre o tema, os alunos puderam saber sobre grandes nomes dos saltos no Brasil tais como: Maurren Maggi, A saltadora foi a primeira mulher brasileira a conquistar uma medalha olímpica no atletismo, o ouro em Pequim. Adhemar Ferreira da Silva que foi primeiro medalhista olímpico da história do Brasil no atletismo. Esses dois atletas geraram grande curiosidade pelo fato deles não terem conhecimento ou alguma informação acerca de ambos.

Ao se iniciar os jogos com os alunos, alguns questionamentos e reflexões surgiram, possibilitando discussões sobre o sentido de saltar, para que serve o saltar? Por que esses atletas saltavam? Depois de muitas respostas e discussões sociais e históricas, construiu-se coletivamente um jogo sobre o saltar historicamente, aonde foi identificado que o homem necessitava transpor diferentes obstáculos com motivações e aspirações diferentes. Assim foi construído um jogo, um lago foi criado e seu objetivo era transpor sem poderem ser atingidos pela agua, aspectos de sobrevivência dos indivíduos dentro de uma perspectiva individual e coletiva, foram determinantes nesse construção, assim como a possibilidade simbólica de ação com elementos históricos, tornaram e foram transversais para um ambiente desafiador e estimulante nos alunos.

O aprender a conhecer se articulou por meio da linguagem corporal, pois ao saltarem os obstáculos puderam se perceber como homens primitivos. Assim sendo, corroborando com a compreensão de Souza (2001, p.27), ao indicar que o "corpo expressa uma linguagem magnífica de comunicação, sendo interna e externamente o primeiro e principal ponto de referência e de diálogo com o mundo”.

A percepção gestual do movimento efetuada com os alunos constituiu de que se aproximaram dos movimentos peculiares de um determinado recorte histórico e cultural, refletindo os utilizados na reconstrução do momento dentro da proposta de saltar. E, nesse contexto, discutiu-se o salto de "tesoura" e o rolo ventral, e a técnica atual o "fosbury flop", está sendo efetuada de costas. Sobre a compreensão da técnica como uma ferramenta construída historicamente, cabe resgatar um conceito cultural de técnica corporal, em que deve ser considerado o significado do movimento dentro de determinada sociedade (Daolio, 2002, Daolio, Velozo, 2008).

Por esse olhar, novamente, criou-se uma situação simbólica e com resgates de vivencias da construção gestual do homem para que os alunos pudessem reajustar suas maneiras de saltar. Nessa perspectiva de interação entre a altura da corda e a ação motora do aluno, ocorriam situações de auto ajuste e auto organização para o ato de saltar sobre e cumprir a tarefa. Por esse olhar, na reciprocidade do aluno com a corda, se percebeu, em muitos, que a técnica de tesoura era automaticamente ajustada para um principio ou tentativa de saltar de costas.

Assim, ainda sobre a situação do lago, esse foi se enchendo e subindo, estimulando aos alunos que saltassem de diferentes formas sobre a corda. Alguns efetuando movimentos próximos dos discutidos anteriormente (rolo ventral, costas). Ressalta-se que o êxito foi um importante elemento destacado nessa atividade, pois a altura da corda condicionava para que todos fossem protagonistas, exigidos suas possibilidades na realização do proposto. 
Esses achados mostram a importância de possibilitar o êxito no processo de ensino, favorecendo a adesão a pratica esportiva. Com esse intuito, deve-se no processo de iniciação ao ensino esportivo, estimular que uma prática exitosa direcione a criança a uma exposição para receber elogios e se destacar (Bettega, Prestes, Lopes, Galatti, 2015), promovendo, com suas conquistas, a autoestima. Nesse aspecto, a relação e a mediação entre docente e discentes, nas atividades percebidas, se estabeleceu de forma horizontal e afetiva para que se promovesse o esporte na escola dentro de sua configuração plena.

Um fato que foi percebido ao se analisar a atividade, que os valores de cooperação e afetividade foram marcantes a medida que a altura do "lago" subia, proporcionando momentos para ampliar aspectos interpessoais. Assim, caminhando na compreensão de que partilhamos um mesmo ambiente, necessitando auxiliar um aos outros, num comportamento ético e numa coletividade comum (Morin, 2000).

Dentro dessa percepção de sobrevivência coletiva, os alunos usavam a estratégia de comunicação e auxílio para que todos pudessem desfrutar da conquista sem burlar as regras estabelecidas. Para Morin (2000, p. 104) "a compreensão é ao mesmo tempo meio e fim da comunicação humana. O planeta necessita, em todos os sentidos, de compreensões mútuas". Como descreve a passagem concomitantemente com a Figura 5:

Figura 5 - Saltar Obstáculos Coletivamente

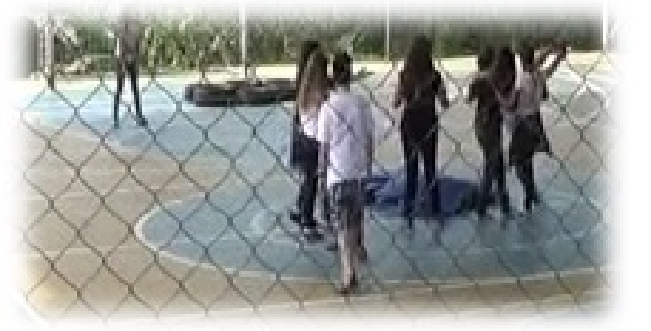

\footnotetext{
[...] os alunos tiveram a sensibilidade de enxergar o outro, tomaram uma pessoa nos braços e carregaram para o outro lado da corda, passando sem cometer erros. Uma aluna, com dificuldades para transpor a altura estabelecida, foi carregada e passou o "lago" para comemoração de todos que partilharam dessa situação. Fonte: arquivo do autor.
}

\section{o atletismo e desenvolvimento humano, o olhar discente...}

Esta última unidade do estudo, foi desenvolvida a partir das reflexões dos alunos no grupo focal que proporcionou estabelecer relações entre as percepções deles com a proposta de intervenção desenvolvida. Foram abordados temas geradores que puderam refletir e avaliar acerca do processo de ensino-aprendizagem, estabelecendo um diálogo claro e de fácil compreensão com os alunos.

Em relação ao elemento lúdico, o jogo foi utilizado como ferramenta para se desenvolver o conteúdo Atletismo e abordar o contexto histórico-cultural. Sobre o jogo, ficou evidente sua aceitação nas falas marcantes dos alunos:

As aulas são muito diferentes do que pensava” (Aluno 2).

"Foram legais (Aluno 11).

Gostei de brincar de homem das cavernas e jogar pedras como os europeus (Aluno 12).

Foram bem cansativas e divertidas, fazia tempo que não suava muito desse jeito, terão novamente? (Aluno 17).

Ao ser oportunizado o aprender o Atletismo, os alunos puderam por meio de jogos e brincadeiras, compreendê-lo por meio de seus movimentos historicamente construídos, corroborando com Freire (2012), que entende o esporte educacional como um ambiente lúdico, no qual o aluno aprende brincando.

Dessa forma, ao utilizar o jogo como ferramenta de ensino, contribui na difusão do esporte em ambiente escolar (Rosa, Souza, Mendes, Wandscheer, Backes, 2017). Assim, o atletismo na intervenção trilhouosa de 
conceitos desconhecidos, acerca do seu conteúdo histórico cultural, sendo ressignificado e percebido, como conteúdo prazeroso e de importância no cenário estudado, como ilustram as falas dos alunos:

Sobre a história do Atletismo eu pude conhecer mais pelos jogos e quando o professor falava, Eu não conhecia uma virgula da história desse esporte (Aluno 16).

Aprendi que o atletismo no Brasil teve bons atletas na última olimpíada (Aluno 13).

Eu gostaria que tivesse atletismo ano que vem, se o professor não trabalhar eu vou pedir, pois acho importante para brincarmos todos juntos (Aluno 14).

Esses achados corroboram com as propostas de ensino esportivo no ambiente escolar, aonde além de promover o movimento esportivo, a compreensão de seus aspectos históricos e culturais, promove suas relações socioeducativas (Machado, Gallati, Paes, 2014). Os discursos dos alunos, também, encontram ressonância nos estudos de Rosa, Souza, Mendes, Wandscheer, Backes (2017) ao ampliarem seus olhares em relação ao atletismo e estabeleceram vínculos sociais por meio dos jogos e brincadeiras experimentadas. Portanto, os achados do possibilitam reflexões sobre as relações entre o corpo, história e cultura, relações sociais e o movimento humano, num movimento de complexidade.

A vivência das atividades de correr, lançar e saltar na proposta pedagógica desenvolvida, compactua para a possibilidade de se perceber o corpo como a essência do ser, a própria manifestação de sua existência, em direta relação com o mundo e com outros (Merleau-Ponty, 2011). Assim, a apropriação da linguagem do Atletismo foi significativamente apreendida ao se propor jogos como uma ferramenta e estratégia para promover a curiosidade de crianças e jovens em aprender sobre esporte.

Dentro dessa ótica, a Figura 6 levanta os temas e jogos desenvolvidos e relaciona com os saberes referentes a história e cultura para o ensino do atletismo, assim como elenca os principais valores percebidos dentro da experiência pedagógica.

Figura 6 - Síntese da relação entre os jogos e o desenvolvimento humano.
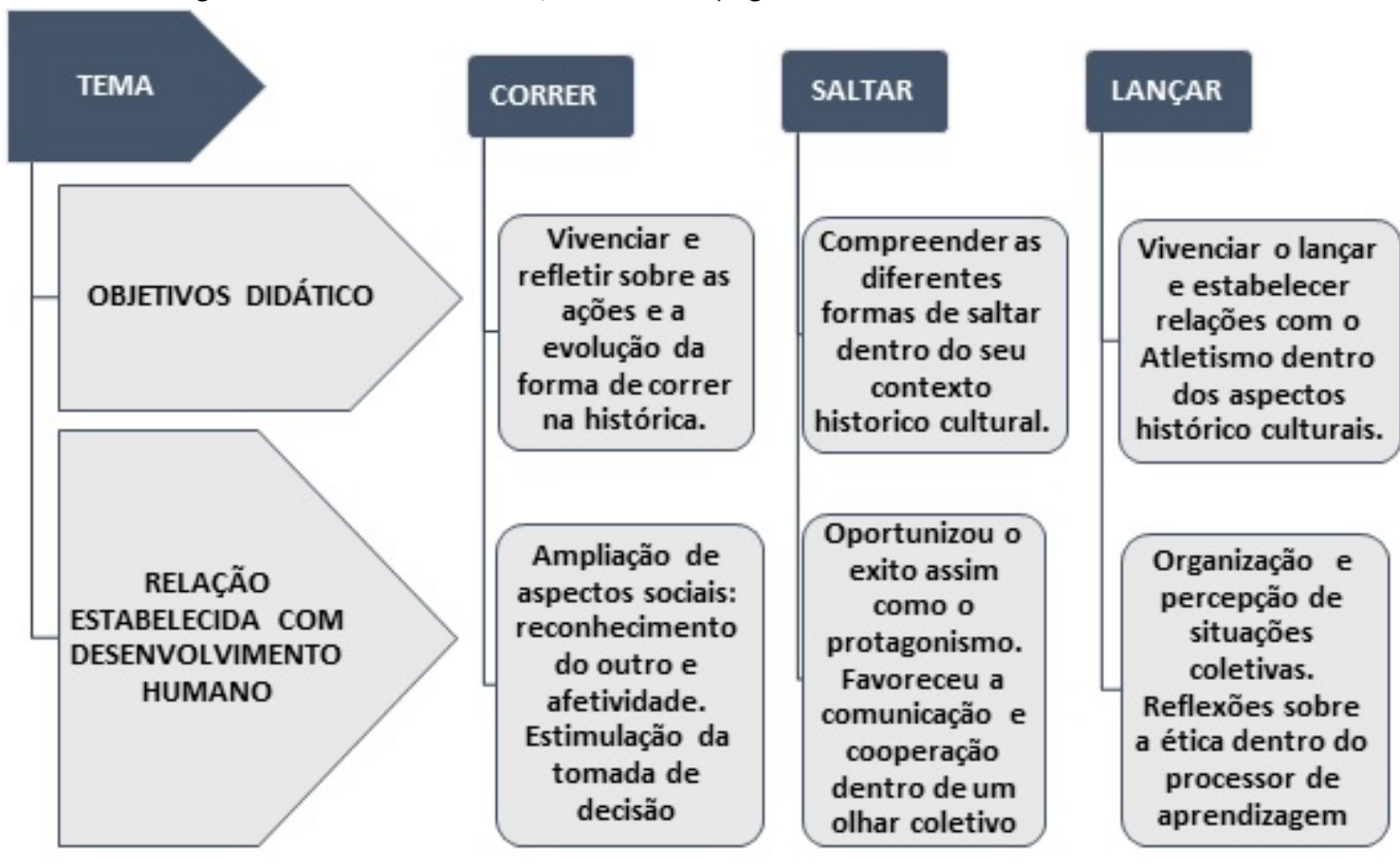

Fonte: os autores. 


\section{Conclusões}

As experiências com o conteúdo histórico e cultural do Atletismo contribuíram para ressignificar, nos alunos envolvidos, essa modalidade nas aulas de Educação Física, enquanto Esporte Escolar.

A sequência didática-pedagógica da proposta aplicada, tendo o jogo como ferramenta de intervenção se mostrou desafiante e estimulante no processo de ensino, sobretudo, na aprendizagem conceitual e técnica de cada prova atlética. As reflexões dos alunos oportunizaram o pensar a práxis, caminhando no sentido de construir uma proposta configurada numa relação de horizontalidade entre docente e discente, problematizando e articulando aspectos da história e cultura da modalidade, no se movimentar do aluno, com sentidos sociais e culturais de como o Atletismo se apresenta hoje como um conteúdo possível de se problematizar acontecimentos históricos e culturalmente construídos em paralelo direto com fatos da sociedade.

Nesse processo de desenvolvimento integral do aluno, compreendendo sua complexidade, partiu-se de uma perspectiva focada na construção de competências e saberes e não na correção de debilidades ou fragilidades (Morais, Koller, 2004). Por isso, acredita-se que o diálogo foi essencial no processo de ensino e aprendizagem do Atletismo, oportunizando valores, respeitando a individualidade dos alunos envolvidos.

A experiência desenvolvida com o Atletismo em ambiente escolar oportunizou aos alunos, sujeitos da intervenção, reflexões e possibilidade de conhecer aspectos históricos e culturais dessa modalidade numa perspectiva fenomenológica, levando-os a um processo de apropriação do conhecimento e de experimentação com concretude de sua essência, comportamentos fundamentais à sua formação crítica, autônoma e cidadã.

Além de desenvolver o conteúdo esportivo, praticar esporte pode oportunizar ao aluno, uma aprendizagem significativa que lhe permita construir valores, possíveis de serem assimilados e transferidos a outros contextos de sua vida (Camiré, Trudel, 2013, Camiré, Trudel, Forneris, 2014).

Por fim, ressalta-se a necessidade de divulgação de estudos relativos ao processo de ensino esportivo no espaço escolar por parte da comunidade acadêmica, que possam estabelecer interfaces entre esporte e desenvolvimento humano, entre a prática didática e a produção científica.

\section{REFERENCIAS}

André, M. H., Mandigo, J. L. (2013) Beyond the Game: Analyzing the usefulness of games to promote life skills development. Pensar a Prática, 16(4), 1256-1270.

Bardin, L.(2011). Análise de conteúdo. São Paulo: Grupo Almedina.

Bettega, O. B., Prestes, M. F., Lopes, C. R., Galatti, L. R. (2015). Pedagogia do Esporte: o jogo como balizador na iniciação ao futsal. Pensar a prática, 18(2), 487-501.

Carlan, P., Kunz, E., Fensterseifer, P. E. (2012). O esporte como conteúdo da Educação Física escolar: Estudo de caso de uma prática pedagógica "inovadora”. Movimento (UFRGS), 18(4), 55-75.

Camiré, M., Trudel, P. (2013). Using High School Football to Promote Life Skills and Student Engagement: Perspectives from Canadian Coaches and Students. World Journal of Education, 3(3), 40-51.

Camiré, M., Trudel, P., Forneris, T. (2014). Examining how model youth sport coaches learn to facilitate positive youth development. Physical Education and Sport Pedagogy, 19(1), 1-17.

Daolio, J. (2002). Jogos esportivos coletivos: dos princípios operacionais aos gestos técnicos - modelo pendular a partir das idéias de Claude Bayer. Revista Brasileira de Ciência e Movimento, 10(4), 99-103.

Daolio, J., Velozo, E. L. (2008). A Técnica Esportiva como Construção Cultural: Implicações para a Pedagogia do Esporte. Pensar a pratica, 11(1), 9-16.

Delors, J. (1998). Educação um tesouro a descobrir - Relatório para a Unesco da Comissão Internacional sobre Educação para o Século XXI. São Paulo: Editora Cortez. 
Duarte, O. (2000). História dos Esportes. São Paulo: MAKRON Books.

Freire, J. B. (2012). Ensinar o esporte, ensinando a viver. Poro Alegre: Mediação.

Freire, J. B., Goda, C. (2008). Fabricando as oficinas do jogo como proposta educacional nas séries iniciais do ensino fundamental. Movimento, 4(1), 111-134.

Gil, A. C. (2008). Métodos e técnicas de Pesquisa Social. São Paulo: Atlas.

Huizinga, J. (1980). Homo ludens: o jogo como elemento da cultura. São Paulo: Perspectiva.

Iora, J. A., Marques, C. L. (2013) O atletismo escolar: proposta de organização de aulas a partir da proposta crítico emancipatória e didática comunicativa. Pensar a Prática, 16(2), 320-618.

Iora, J.A., Fiorenza, M. C., Rios, K. R. y Rosa, R. S. (2016). A Construção de Materiais e a Utilização de Espaços Alternativos para o Ensino do Atletismo. Saude e desenvolvimento humano, 4(2), 79-88.

Kunz, E. (2001). Transformação didático-pedagógica do esporte. Ijuí: Unijuí.

Leontiev, A. N. (1978). Sobre o desenvolvimento histórico da consciência. In A.N. Leontiev. O desenvolvimento do psiquismo (pp. 89-142). Lisboa: Horizonte Universitário.

Machado, G. V., Galatti, L. R., Paes, R. R. (2014). Pedagogia do esporte e o referencial his-tórico-cultural: Interlocução entre teoria e prática. Pensar a prática, 17, 414-430.

Mauad, A. M. (2004). Fotografia e história: possibilidades de análise. In M. Ciavatta y N. Alves (org.). A leitura de imagens na pesquisa social: história, comunicação e educação (pp. 19-36). São Paulo: Cortez.

Merleau-Ponty, M. (2011). Fenomenologia da percep̧̧ão. São Paulo: Martins Fontes.

Morais, N. A., Koller, S. H. (2004). Abordagem ecológica do desenvolvimento humano, psicologia positiva e resiliência: Ênfase em saúde. In S. H. Koller (Ed.), Ecologia do desenvolvimento humano: Pesquisa e intervenção no Brasil (pp. 91-107). São Paulo: Casa do Psicólogo.

Morgan, D. (1996). Focus Groups. Annual Review Sociology, 22,129-152.

Morin, E. (2000). Os sete saberes necessários à educação do futuro. São Paulo: Editora Cortez.

Oliveira, A. (2008) A participação do atleta negro no esporte: das pistas de atletismo às pistas de Fórmula 1. Lecturas, Educación Física y Deportes. Disponível em http://www.efdeportes.com/efd126/a-participacao-do-atleta-negro no-esporte.htm.

Rosa, R. S., Souza, E. R., Mendes, F. G., Wandscheer, R., Backes, A, F. (2017). Atletismo como conteúdo foi a escola: olhares discentes sobre a experiência de ensino. Pensar a Prática, 20(1),15-25.

Souza, E. R. (2001). Do corpo produtivo ao corpo brincante: o jogo e suas inserçöes no desenvolvimento da criança (Tese Doutorado). Universidade Federal de Santa Catarina, Florianópolis, SC, Brasil. 